\title{
Resonance classification of mixed assemblages of fish with swimbladders using a modified commercial broadband acoustic echosounder at $1-6 \mathrm{kHz}$
}

\author{
Timothy K. Stanton, Cynthia J. Sellers, and J. Michael Jech
}

\begin{abstract}
Recently developed broadband acoustic methods were used to study mixed assemblages of fish spanning a wide range of lengths and species. Through a combination of resonance classification and pulse-compression signal processing, which provides for high-range resolution, a modified commercial broadband echosounder was demonstrated to provide quantitative information on the spatial distribution of the individual size classes within an assemblage. In essence, this system spectrally resolves the different size classes of fish that are otherwise not resolved spatially. This method reveals new insights into biological processes, such as predator-prey interactions, that are not obtainable through the use of a conventional narrowband high-frequency echosounder or previous broadband systems. A recent study at sea with this system revealed aggregations containing bladdered fish $15-30 \mathrm{~cm}$ in length (Atlantic herring (Clupea harengus) and silver hake (Merluccius bilinearis)) and a variety of species of smaller fish $2-5 \mathrm{~cm}$ in length. These observations infer that the smaller $2-5 \mathrm{~cm}$ fish can be colocated in the same aggregations as their predator, the larger silver hake, as well as pre-spawning herring. While this technological advancement provides more information, there remain challenges in interpreting the echo spectra in terms of meaningful biological quantities such as size distribution and species composition.
\end{abstract}

\begin{abstract}
Résumé : Des méthodes acoustiques à large bande récemment mises au point nous servent à étudier des peuplements mixtes de poissons couvrant un large éventail de longueurs et d'espèces. Par une combinaison de classification des résonances et de traitement des signaux de compression des impulsions qui fournit un haut degré de résolution, un échosondeur commercial modifié à large bande s'avère capable de fournir des données quantitatives sur la répartition spatiale des classes d'âge individuelles au sein d'un peuplement. Spécifiquement, le système permet une résolution spectrale des différentes classes de taille des poissons qui autrement ne peuvent être distinguées dans l'espace. La méthode ouvre de nouvelles perspectives sur les processus biologiques, tels que les interactions prédateurs-proies, qu'on ne peut obtenir par l'emploi d'un échosondeur ordinaire de haute fréquence à bande étroite, ni par les systèmes à large bande plus anciens. Une étude récente en mer avec ce système montre des rassemblements de poissons à vessie natatoire de longueurs de 15 à $30 \mathrm{~cm}$ (harengs atlantiques (Clupea harengus) et merlus argentés (Merluccius bilinearis)), ainsi qu'une variété d'espèces de poissons plus petits de longueurs de $2-5 \mathrm{~cm}$. Ces observations laissent croire que les poissons plus petits de $2-5 \mathrm{~cm}$ peuvent être localisés ensemble dans les mêmes rassemblements que leurs prédateurs, les merlus de plus grande taille et les harengs avant la fraie. Bien que cette avancée technologique fournisse plus d'information, il reste des défis pour interpréter les spectres des rétrodiffusions en regard de quantités biologiques significatives, telles que la répartition en taille et la composition en espèces.
\end{abstract}

[Traduit par la Rédaction]

\section{Introduction}

Fish are commonly studied through a combination of nets and acoustic echosounders (Medwin and Clay 1998; Simmonds and MacLennan 2005). Nets provide information regarding species composition, biological aspects (length, mass, maturity, sex, diet, and age), and, to some degree, spatial distribution. Echosounders provide contiguous, high-resolution information on the spatial distribution of fish throughout the insonified water column. Each approach has limitations, which is why they are used in concert. For example, nets have selectivity and catchability issues (Hoffman et al. 2009) and can under-sample the spatial structure of fish aggregations. In the case of echosounders, significant ambiguities in interpretation can occur, especially when narrowband sound is used (Stanton et al. 2010). When used together, nets provide "point" samples of fish, while the acoustics data are synoptic and can be used to "connect" the point samples at high resolution.

Received 29 April 2011. Accepted 19 December 2011. Published at www.nrcresearchpress.com/cjfas on 19 April 2012.

J2011-0170

T.K. Stanton and C.J. Sellers. Woods Hole Oceanographic Institution, Applied Ocean Physics and Engineering Department, 98 Water Street, MS 11, Woods Hole, MA 02543, USA.

J.M. Jech. National Marine Fisheries Service, Northeast Fisheries Science Center, 166 Water Street, Woods Hole, MA 02543, USA.

Corresponding author: Timothy K. Stanton (e-mail: tstanton@whoi.edu). 
For monospecific assemblages of fish containing a narrow distribution of sizes, the combination of nets and narrowband echosounders has been successful in providing abundance estimates. In this case, size and orientation distributions are assumed to be known, so the echo can be related directly to numerical density. However, for the case of mixed species assemblages where there is a wide distribution of sizes, the ambiguities of confounding fish size and species cannot be eliminated with narrowband acoustics (Horne and Jech 1999). In this case, there are more variables (e.g., size distribution, species-dependent scattering properties, and orientation distribution) than the single-frequency data can adequately infer. In essence, this is an under-determined problem (Holliday 1977a; Stanton et al. 2010).

Sizes of fish with swimbladders were originally studied and, in some cases, spectrally discriminated, through the use of broadband sound as early as the1940s by Hersey, Backus, and others, as briefly reviewed in Chapman and Marshall (1966). The work involved the use of broadband sound in the upper hundreds of hertz to low kilohertz frequencies to exploit the resonance of the swimbladder. Since some species of fish do not have swimbladders, the technique did not apply to those fish. Later studies on this topic were conducted by numerous investigators, including Holliday (1972), Hall (1981), and Thompson and Love (1996). Given the importance of the early studies, the methods were expanded to operations around the globe (Chapman et al. 1974). In those studies (except for some reported in Holliday 1977b), explosive charges were used to create the broadband sound. Some of the data reported in Holliday (1977b) were collected with a seismic arcer as an acoustic source. Chapman and Marshall (1966) observed up to three resonance peaks in an aggregation of fish in the North Atlantic. Because the resonance frequency depends upon the volume of the swimbladder, which in turn is related to the size of the fish, the results suggested the presence of three size classes of fish.

A major advantage of broadband sound is that more acoustic information is available, allowing the size classification of mixed assemblages of fish. A major disadvantage of the early approaches was the use of explosives. In addition to being dangerous to handle, explosives could not be used frequently enough to precisely map the spatial distribution of the fish. Furthermore, the source signal was not consistent from explosion to explosion, causing challenges in the interpretation of the data. The latter shortcomings are also associated with a seismic arcer. Prototype hardware involving piezoelectric transducers helped address those issues with multiple closely spaced, discrete frequencies spanning the range of resonance of Atlantic herring (Clupea harengus; Nero et al. 2004).

The above work, which all involved backscattering of sound, has been complementary to that of Diachok and colleagues, who have used a wide range of frequencies to measure the attenuation of sound due to the presence of fish with swimbladders (Diachok et al. 2001; Diachok 2002, 2005). In this geometry, the source and receiver are separated by a large distance. Strong peaks in transmission loss have been connected to the size and depth of the fish present. Because of the wide range of frequencies used, different sizes of fish can be discriminated within the same aggregation.

Recently, new broadband acoustic methods were developed that are superior to conventional narrowband systems and pre- vious broadband systems (Stanton et al. 2010). A commercial broadband echosounder was adapted so that its lowest frequency channel could be used for resonance classification of swimbladder-bearing fish. This system, which uses piezoelectric transducers, produces high-quality, controlled source signals that are consistent from ping to ping. Using a sequence of one ping per 1-2 s, this downward-looking towed system can be used to routinely study the spatial distribution of fish at high resolution. The high (range) resolution is obtained through pulse-compression processing, and the observed spectral peaks associated with resonances from each major size class can be studied (within the limits of the bandwidth of the system) individually within an aggregation.

This approach is superior to narrowband systems because of the significant information obtained through the broadband signals, such as spectral resolution. Furthermore, it is superior to all previous broadband systems cited above because of the combination of a controlled transmit signal, a transmit repetition rate of one ping per 1-2 s, and pulse-compression processing, resulting in the ability to routinely map the interior of aggregations. With those previous systems, the aggregations could not be studied at high spatial resolution because of the lack of a controlled transmit signal, a low repetition rate of transmit signal, and (or) the lack of pulse-compression processing, thus preventing measurement of detailed information on relative location of different size classes. Although technologically superior to the previous systems, there remain the same issues associated with interpreting the resonances as with the other systems. In the first use of the new system at sea, monosized, monospecific aggregations of fish were studied, and a single resonance peak was observed (Stanton et al. 2010).

More recently, a near-identical replacement of the Stanton et al. (2010) broadband system and associated new methods were used to study mixed assemblages of fish in the ocean. First-of-a-kind results are given in this paper, where size classes of fish are spectrally resolved that would otherwise not be resolved spatially. In two examples, strong spectral peaks at two frequencies were resolved within aggregations of fish, corresponding to resonances from two major size classes. The spatial distributions of the two size classes are inferred within each aggregation. A possible third resonance, detected in the "shoulder" of one of the strong peaks, is also explored. Modeling of the resonances is conducted to infer numerical densities of each size class. Challenges associated with interpreting the spectral information in terms of meaningful biological parameters such as size distribution are discussed. Parts of this work were first presented in Gauss et al. (2009).

\section{Materials and methods}

\section{Experiment and broadband calibration}

The study was conducted over Georges Bank, east of Cape Cod, Massachusetts, USA, during the period 9-19 September 2008. The study was part of the annual survey of Atlantic herring by the US National Marine Fisheries Service (NMFS). Two ships were used: (i) the FR/V Delaware II (NMFS vessel), which deployed a pelagic rope trawl to sample the fish (mouth opening of $300-350 \mathrm{~m}^{2}$ when towed at 4-5 kn) and also used high-frequency narrowband 
echosounders mounted on the hull (Jech and Michaels 2006), and (ii) the R/V Endeavor, which towed the broadband echosounder for resonance classification of the fish. The study was conducted in a $5 \mathrm{~km} \times 5 \mathrm{~km}$ area in the northwest section of the bank in water depths of approximately $200 \mathrm{~m}$. Both ships conducted many concurrent transects in the same area, although normally along different paths. The net tows were typically $3-8 \mathrm{~km}$ long, including deployment and retrieval. The longer tows corresponded to when fish near the seafloor ( 200 m deep) were sampled. The median distance covered while at the desired depth (all tows) was $2.5 \mathrm{~km}$.

The broadband acoustic system (Edgetech) is a nearly identical replacement to the one described in Stanton et al. (2010). The major difference relevant to this study is that, although the lowest frequency channel uses the same type of transmitting and receiving sensors as the predecessor (resulting in the same beam widths), a chirp transmission signal was used with a $100 \mathrm{~ms}$ duration (vs. $10 \mathrm{~ms}$ before) and spanned the frequency range $1-6 \mathrm{kHz}$ (vs. $0.5-14 \mathrm{kHz}$ before). In addition, the transmitter was mechanically isolated from the towbody. Consequently, the system had a signal-tonoise ratio (SNR) that was superior to that of the original system. The SNR of the replacement system was typically 10-25 dB across the frequency band while being towed routinely near the surface (typically $10-20 \mathrm{~m}$ below the surface at $3.5 \mathrm{kn}$ speed) and imaging aggregations of fish throughout the entire water column. As with the original system, the new system could also be deployed to approximately $150 \mathrm{~m}$ deep at the same tow speed to study fish at shorter ranges. This improved the resolution, allowing individual fish to be resolved as well as further improving the SNR (Stanton et al. 2010). Also, the 1-6 kHz pulse was temporally compressed through a cross-correlation method to provide a range resolution of approximately $20 \mathrm{~cm}$ (Stanton et al. 2010).

As with the previous system, the system response is not uniform across the 1-6 kHz band. The response drops rapidly below $1.5 \mathrm{kHz}$, heretofore referred to as the lower "band edge", although strong echoes can still be detected in the $1.0-1.5 \mathrm{kHz}$ range, such as in some examples in this paper.

The system was calibrated at sea at the operational depth using a standard spherical target and the new broadband calibration methods described in Stanton and Chu (2008) and Stanton et al. (2010). The difference here was the use of a $30 \mathrm{~cm}$ diameter solid $\mathrm{Al}$ sphere (vs. $20 \mathrm{~cm}$ before), which provided a stronger echo and resulted in a detectable signal across the entire frequency band. Since the scattering resonances of the sphere were weak in the $1-6 \mathrm{kHz}$ range, the spectral response was smoothly varying, and a full-wave calibration (defined in Stanton and Chu 2008) was performed in this frequency band.

\section{Data processing and modeling}

The pulse-compressed broadband echoes were converted to standard units of volume backscattering strength as a function of frequency through the use of the equations derived in Stanton et al. (2010). Once the peaks in the spectral data were identified, predictions of volume backscattering strength were made with the purpose of inferring the numerical density $N$ of the size class corresponding to each peak. The predictions were made using the equations and assumptions presented in Nero et al. (2004).
In Nero et al. (2004), the swimbladder of each fish was assumed to dominate the scattering at these frequencies, and the remainder of the fish was assumed to contribute a negligible amount to the scattering. The swimbladder is modeled as a prolate spheroid with its ends fixed, as given in more detail below. The general equations from Love (1978) were simplified in Nero et al. (2004) by (i) keeping the dominant damping terms related to acoustic radiation and viscosity and ignoring thermal damping and (ii) ignoring tension of the swimbladder wall in the calculation of resonance frequency. Also, as in Nero et al. (2004), only first-order scattering is assumed with no extinction, the resonance properties of the individual fish are assumed to not be affected by the presence of neighboring fish, and a simple incoherent summation of the backscattering cross-sections of the individual fish was made. The first two assumptions are valid because of the relatively low densities of fish observed in this study (fish separations of the order 5-25 body lengths), and the third is from the fact that the distributions of the fish are random and do not resemble a crystalline lattice (Feuillade et al. 1996; Nero et al. 2007; Hahn 2007). There is a typographical error in Nero et al. (2004) in the factor, $\zeta$, that corrects the resonance frequency for the nonspherical shape of the swimbladder. The correct form is given in eq. 8 of Love (1978) (and also given by Ye 1997), which was used in this paper.

Note that the spectral peaks referred to throughout this paper are those observed from a distribution of sizes of fish. Specifically, for a given depth, a peak from a distribution of fish is due to the summed signals of scattering by individual fish, each with a different resonance frequency due to its different size. The width of a spectral peak from a distribution of fish will be wider than that of an individual fish, owing to the width of the size distribution.

Modeling the resonance of the swimbladder required separating the fish into two major groups - physostomes and physoclists (reviewed in Diachok 2005). In the former case, the volume of the swimbladder changes with depth approximately following Boyle's law, which, in turn, contributes to changes in the resonance frequency of the swimbladder (5/6 power of ambient pressure). In the latter case, the volume of the swimbladder remains constant for each fish size (given no rapid changes in depth), resulting in a resonance frequency that is more weakly dependent upon depth than it is in the physostomes (1/2 power of ambient pressure).

In addition to accounting for change in the volume of the physostome swimbladder as a function of depth, the possible change in shape must also be considered. In spite of significant anatomical evidence that the length of the swimbladder might be constrained (and possibly "fixed") as the swimbladder shrinks with increases in depth, there is compelling empirical evidence in measurements of resonance frequency that the swimbladder shrinks uniformly (i.e., a "free" swimbladder), as reviewed in Diachok (2005). Contrary to that review, but involving data collected at much higher frequencies, in a study by Gorska and Ona (2003), the length of the swimbladder of herring (a physostome) was inferred to remain fixed as the depth of the herring increased to $300 \mathrm{~m}$. The inference was made through modeling the swimbladder as a deformed finite cylinder, of fixed length, with the crosssectional radius varying according to Boyle's law. However, these latter acoustic studies do not directly relate to this cur- 
rent study, as the studies were conducted at frequencies well above resonance, where the scattering was dominated by the surface of the dorsal side of the swimbladder, not its volume. The correction factor for resonance frequency associated with changes in shape would vary on the order of several tens of percentage points over the entire depth. To be consistent with the Nero et al. (2004) analysis that used the fixed-length constraint, the length of the swimbladder for the modeling of herring is held constant (with the cross-sectional radius varying according to Boyle's law).

For simplicity and owing to lack of detailed information on each species of fish, the volume, $V$, of the swimbladder of all fish at the surface was assumed to vary according to the 3.35 power of fish length, $L$, using the formula $V=A L^{3.35}$ (where $V$ is in $\mathrm{cm}^{3}$ and $L$ is in $\mathrm{cm}$ ) in the same manner used by Nero et al. (2004) for Atlantic herring, where the mass was related to length. Different values of the coefficient, $A$, in this relationship were used for each of the following size classes of fish - Atlantic herring (19-29 cm), silver hake (Merluccius bilinearis, 15-30 cm), and a mix of species of small fish (2$5 \mathrm{~cm}$ ). This coefficient was chosen based on the best fit between scattering predictions and data. In essence, empirical determination of this parameter involved information concerning the acoustically determined volume of the swimbladder. Through this process, and to maintain a best fit, the coefficient varied between two samples from different depths within the same class of fish. Also, because the volume of the physostome swimbladder changes with depth, the constant is determined for the volume at the sea surface using data from the deeper depths and extrapolation through Boyle's law.

Another modeling constraint involved the quality factor, $Q$, which is defined as the resonance frequency divided by the width of the resonance curve (from an individual fish) and depends upon the damping term, $\xi$ (same notation as in Nero et al. 2004), of the fish. Other studies demonstrated that the quality factor of resonant fish is normally a single-digit number, of the order $1-5$. These studies include resonance measurements with a fixed depth of fish (Batzler and Pickwell 1970; McCartney and Stubbs 1970) and later measurements, where the depth of the fish was varied and depth dependence of resonance properties and adaptation of those properties to changes in depth were studied (Sand and Hawkins 1973; Sundnes and Sand 1975; Løvik and Hovem 1979). The constraint on the quality factor imposed a corresponding restriction upon $\xi$.

\section{Inferring parameters from the data}

Inferences of biological and acoustical parameters from the data, based on the modeling described above, involved directly using the size distribution observed in the trawl samples. This constraint then dictated other aspects of the modeling. In essence, this is a three-parameter fit of the model to the data, which concerns center frequency, amplitude, and width of the spectral peaks. The three parameters, $A, N$, and $\xi$, are inferred from the fit with the constraint on $Q$, and hence $\xi$, as mentioned above.

A potential source of error is that there were nonconcomitant acoustic and trawl sample volumes. To address this issue, trawl data were categorized and combined according to day, night, shallow tow, and deep tow and used as the basis for the acoustic modeling.

The modeling process began by summing the scattering contributions from each length within a length distribution (corresponding to a given length class) based directly upon the trawl data. If there was more than one length distribution contributing to the scattering in a given acoustic sample window, then the contributions from each length distribution were combined to form the final scattering curve for that sample window. For each length distribution, the three parameters were varied as part of the curve-fitting process in the following order: ( $i) A$ was varied to match the modeled frequency of the spectral peak of the length class with the observed frequency; (ii) $N$, applied uniformly to each length distribution, was varied so that the amplitude of the modeled spectral peak matched the observed amplitude; and (iii) $\xi$ was varied in the model to match the width of the observed spectral peak.

The width of the peak from the scattering associated with a size class is due to a combination of the width of the length distribution and the inherent damping of each individual fish. The damping term is associated with the damping from the individual fish and was varied to increase the width of the collective resonance scattering curve beyond the width solely due to the length distribution. To be consistent with the studies cited above, the damping term was restricted so that the resultant quality factor for the individual fish was kept at or below a value of 10 . Also, since varying $\xi$ also results in a change in the amplitude of the peak, the numerical density was changed again, in an iterative manner. Numerical density of each of the three size classes of fish was allowed to vary freely without bounds.

As part of the calculations, an error term was calculated (sum of the square of the difference between the scattering prediction and data, on a linear scale). The terms $A, N$, and $\xi$ were varied until the error term was minimized.

\section{Results}

\section{Acoustic measurements}

Assemblages of fish were observed in the acoustic data both near the seafloor and in the upper water column (Figs. 1 and 2). The volume backscattering strengths measured with the broadband echosounder contained strong resonances in all aggregations (day and night; upper water column and near the seafloor). In a study of 12 aggregations in the study area, sections within aggregations were selected, and the frequency at which each spectral peak occurred was extracted (Fig. 3). This peak is associated with resonances of the fish swimbladders. Generally, there was a single peak in the data involving the fish near the seafloor at about $2.7 \mathrm{kHz}$, and there were two major peaks in the data from the upper water column at about 1.5 and $3.7 \mathrm{kHz}$. There were generally a comparable number of peaks at $1.5 \mathrm{kHz}$ as at $3.7 \mathrm{kHz}$ in each aggregation in the upper water column, as is illustrated for aggregations $\mathrm{E}$ and $\mathrm{J}$ (Fig. 2). There were also several aggregations or portions of an aggregation (all upper water column) in which there were far more of the peaks at $1.5 \mathrm{kHz}$ than at $3.7 \mathrm{kHz}$. This occurred near 80-130 m depth (e.g., the open and closed triangles in Fig. 3).

The nighttime acoustic data from the upper water column 
Fig. 1. Echograms of compressed-pulse signals (1-6 kHz frequency band) and $S_{V}$ versus frequency for two aggregations. (a) and (c) showing aggregation RT4 near the seafloor during the early morning daylight. $(b)$ and $(d)$ showing aggregation $\mathrm{J}$ in the upper water column at night. Note that the vertical axes scales in $(a)$ and $(b)$ are different. The echograms are plotted on a relative scale in which red and blue correspond to stronger and weaker echoes, respectively. The values of $S_{v}$ given in $(c)$ and $(d)$ correspond to the sample windows shown in $(a)$ and $(b)$, respectively.
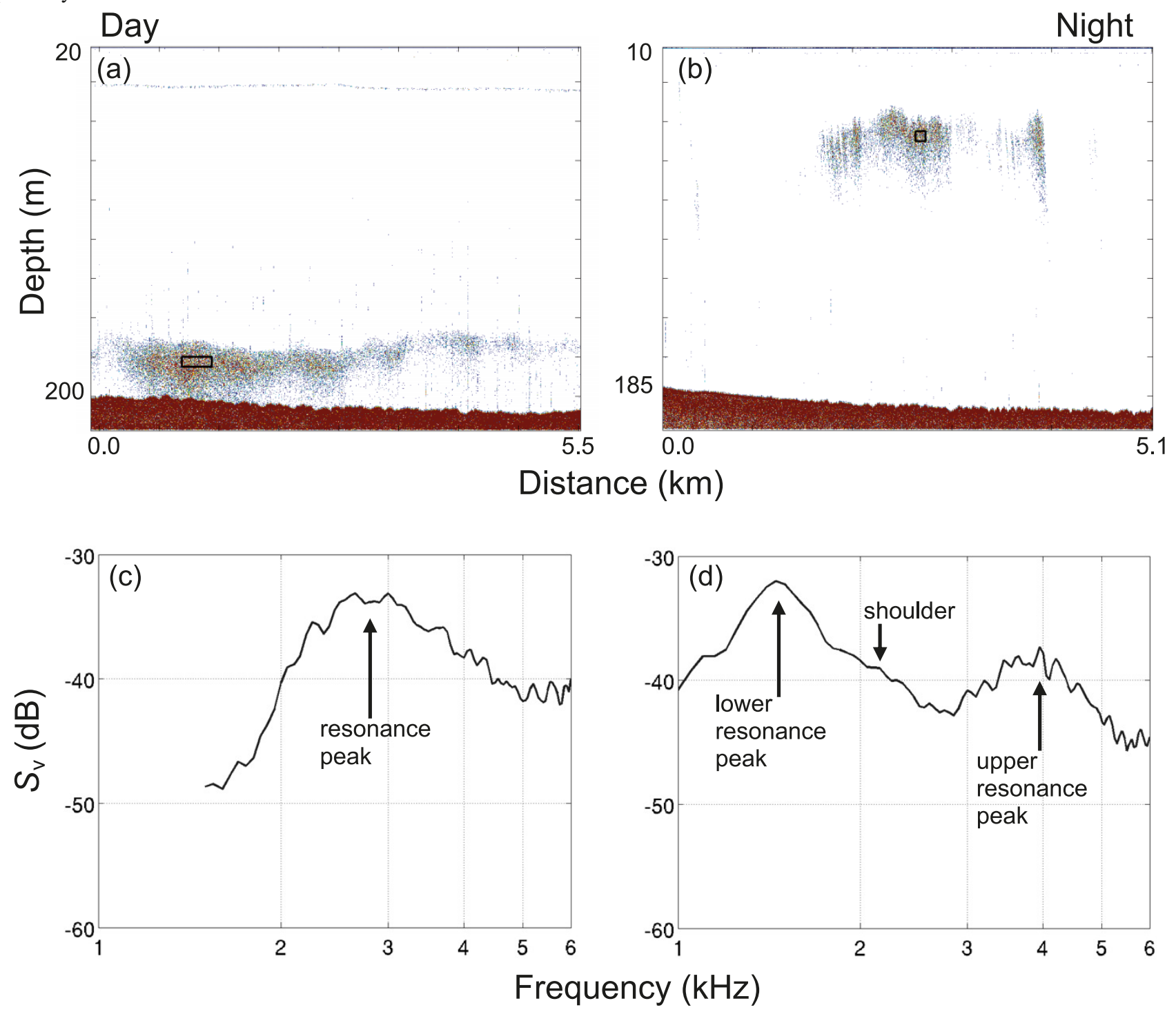

were examined in detail by constructing the equivalent of echograms of volume backscattering strength as measured at each of the two major peak frequencies (Fig. 2). Data from two aggregations ( $\mathrm{E}$ and $\mathrm{J}$ ) were examined, where each aggregation was subdivided into sampling windows of $5 \mathrm{~m}$ depth and about $160 \mathrm{~m}$ length. All window depths reported are the mean depth of the window; thus the depth range of the sample window is the mean depth $\pm 2.5 \mathrm{~m}$. In each case, the volume backscattering strength associated with the lower resonance frequency (that is, due to the larger fish) remained within a 6-7 $\mathrm{dB}$ range of values throughout the aggregation, with peak values occurring at the mid-depth portions of the aggregation and decreasing toward the upper and lower extremes. In contrast, although the volume backscattering strength associated with the higher peak frequency (that is, due to the smaller fish) similarly remained within a 6-7 dB range in aggregation $\mathrm{E}$, there were changes of $14 \mathrm{~dB}$ versus depth in aggregation J. Specifically, the volume backscattering strength in aggregation $\mathrm{J}$ for the higher resonance frequency decreased with depth from the mid-depth peaks by about 14 versus $7 \mathrm{~dB}$ for aggregation $\mathrm{E}$.

Depth dependencies of the resonances were also examined (Fig. 3). Some of the data (aggregation B) showed the spectral peak at $2.7 \mathrm{kHz}$ at the deep depths (near the seafloor) having a general trend in which the peak frequency decreased monotonically with decreasing depth, approximately according to Boyle's Law (which results in a resonance frequency depending upon a 5/6 power of depth), toward a value of $1.5 \mathrm{kHz}$ at the shallower depths. At the shallower depths (upper water column), the $1.5 \mathrm{kHz}$ peak frequency data had two trends - one to increase with increasing depth (indicated by the arrow labeled "2", Fig. 3) and one in which it did not vary with depth (indicated by the arrow labeled "1", Fig. 3). The data following this latter (depth-independent) 
Fig. 2. Acoustic scattering data from two aggregations, E and $\mathrm{J}$ : $(a)$ and $(b)$ showing echograms of compressed-pulse signals (1-6 kHz frequency band); $(c)$ to $(f)$ showing "echograms" of volume backscattering strength, $S_{V}$, based on sample windows shown in corresponding top panels, of the lower and upper resonance peaks, as indicated. The $S_{V}$ color scale for $(c)$ to $(f)$ is given at the bottom. The echograms in $(a)$ and (b) are on a relative scale, with red and blue corresponding to stronger and weaker echoes, respectively.

\section{Aggregation J}

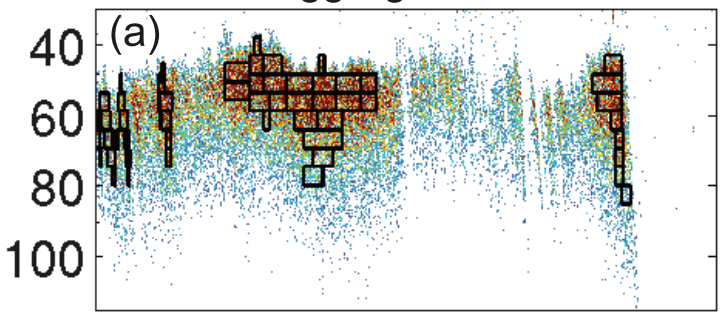

Aggregation E

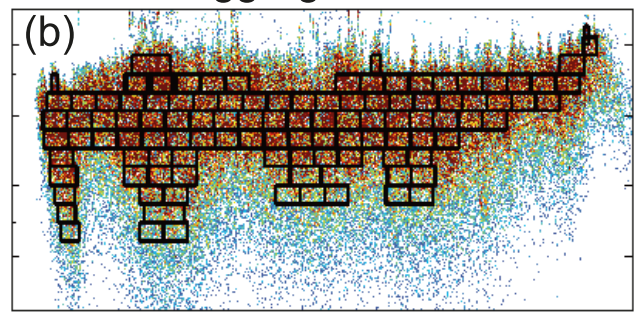

\section{Lower resonance peak}
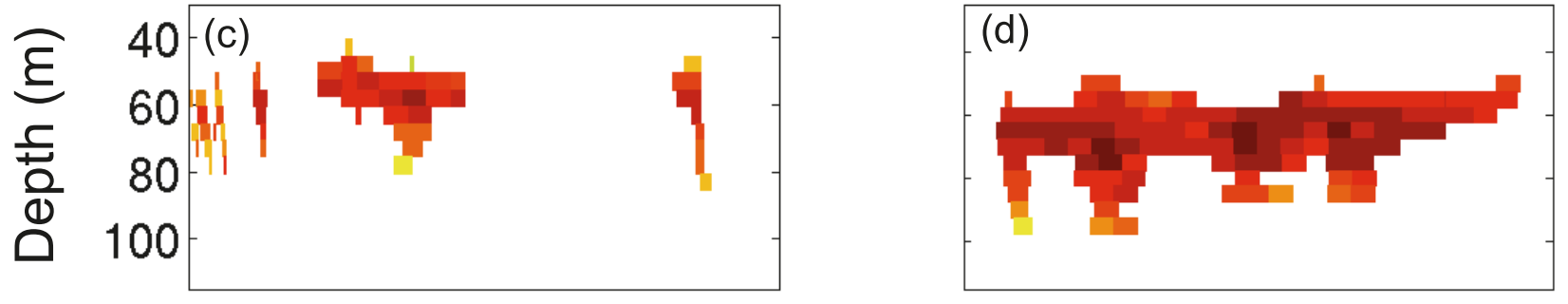

Higher resonance peak
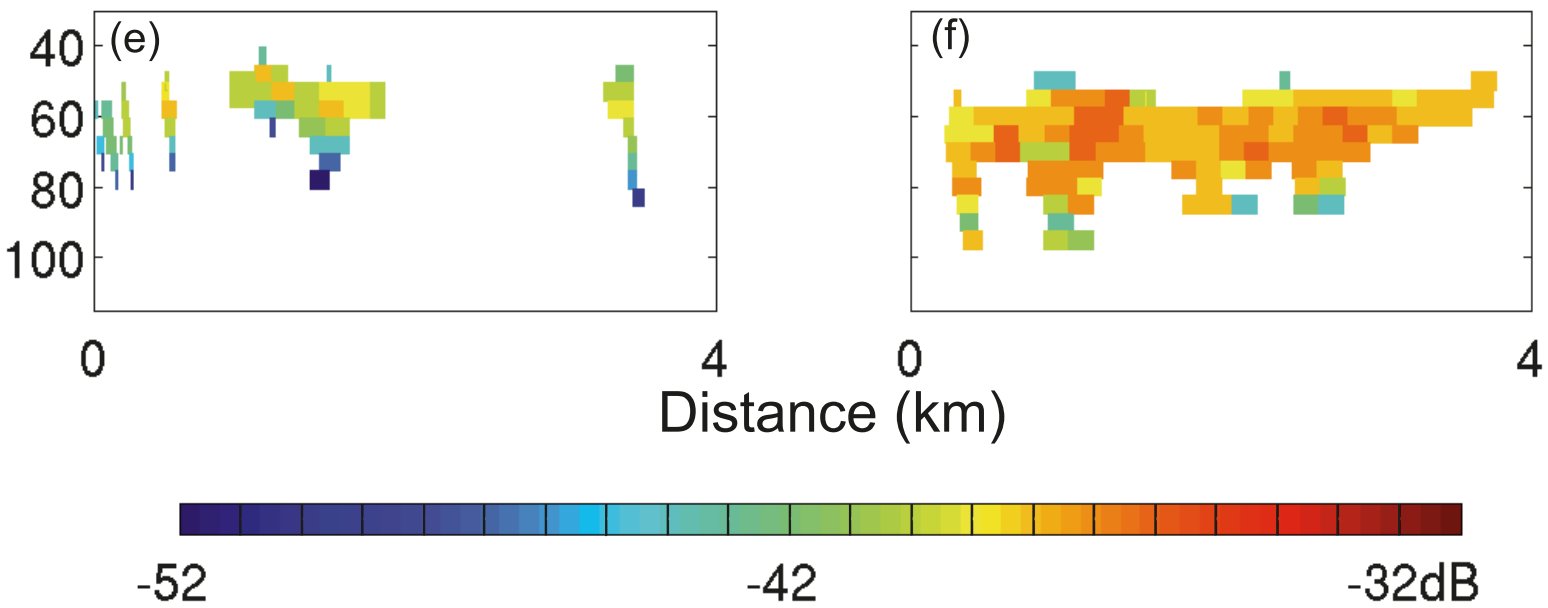

trend were observed down to depths below the surface of $125 \mathrm{~m}$. The $3.7 \mathrm{kHz}$ peak frequency observed in the upper water column did not show depth dependence. The peak frequency in this case varied $( \pm 200 \mathrm{~Hz})$ around the mean value of $\sim 3.7 \mathrm{kHz}$. Given the fact that more than one depth dependence was present in some data, a regression analysis of the dependencies was not conducted, since it would be subject to a qualitative selection of subsets of data.

A significant complicating factor in the data (some of which are analyzed below) involved the fact that the lower edge of the frequency band of the system was at about $1.5 \mathrm{kHz}$ (Fig. 3). The SNR was generally quite acceptable (up to $\sim 30 \mathrm{~dB}$ ) for strong peaks near $1.5 \mathrm{kHz}$, especially for the data involving shorter ranges. Furthermore, for the shortrange data illustrated, the SNR decreased for frequencies below $1.5 \mathrm{kHz}$ to $15 \mathrm{~dB}$ at $1.0 \mathrm{kHz}$, which is still an acceptable value (Fig. 1d). However, the slope of the transducer re- sponse in the range $1.0-1.5 \mathrm{kHz}$ was large, which no doubt caused error in the calibration in that range and, hence, error in identifying the resonance peak near those frequencies. This effect associated with system sensitivity near the band edge probably contributed to at least some of the apparent independence upon depth of the resonance frequencies at $1.5 \mathrm{kHz}$.

\section{Trawl samples}

Trawl samples showed that there were two major size classes of fish in the area spanning multiple species, the vast majority of which contained swimbladders (Fig. 4). The sizes involved smaller fish (fork length, $L \sim 2-5 \mathrm{~cm}$ ) and larger fish (mean $L \sim 25 \mathrm{~cm}$ ). Illustrated are all data combined from 17 tows that were conducted day and night and throughout the entire water column, the combined data from 5 tows conducted at night in the upper water column (20- 
Fig. 3. Peak frequencies associated with resonances as measured within sample windows within various aggregations, at various depths and times of day (closed symbol, daylight; open symbol, nighttime). Data from different aggregations were assigned the same symbol when they were collected during the same day (first light through early morning) or the same night (when it was completely dark). At the shallower depths (40-90m), two peaks were generally observed in each aggregation. Three points ("1", "2", and " 3 ") are identified, which are analyzed later. Three theoretical curves are superimposed, representing two functional dependencies of resonance frequency versus depth. The band edge, which occurs at $1.5 \mathrm{kHz}$, is represented by the horizontal broken line.

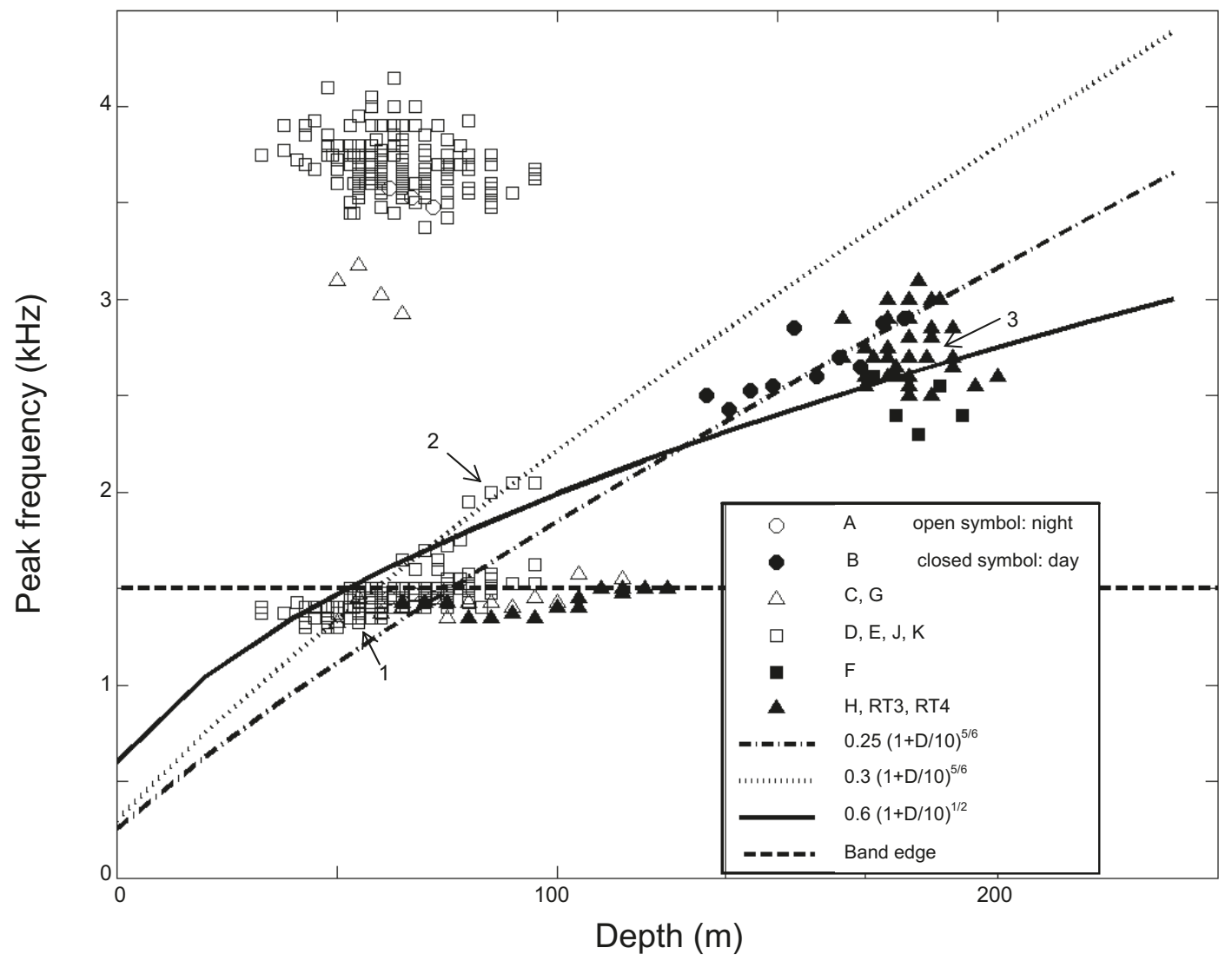

$150 \mathrm{~m}$ deep), and the data combined from 6 tows near the seafloor (180-200 $\mathrm{m}$ deep) conducted during the day (Figs. $4 a, 4 b$, and $4 c$, respectively). The samples collected from the upper water column at night contained two major size classes, with the larger size class dominated by Atlantic herring (physostome) and also containing silver hake, and the smaller size class containing several species (Acadian red fish (Sebastes fasciatus), silver hake, red hake (Urophycis chuss), white hake (Urophycis tenuis), butterfish (Peprilus triacanthus), and pearlside species (Maurolicus spp.), all physoclists). These species constituted $95 \%-100 \%$ of the species composition in all but two tows. In these two tows, juvenile goosefish (Lophius americanus) made up 15\% and $18 \%$ of the catch (nine and six individuals, respectively). The juvenile goosefish were not included in the analysis as they do not have a gas-filled swimbladder.

Samples intended to be collected principally near the seafloor showed two size classes of fish as well. However, as the nets passed through the upper water column layer on the way to and from the seafloor with the net open, fish were most likely caught in the upper water column. Echograms (not shown) confirmed the presence of a scattering layer in the upper water column during each of the tows near the bottom. From past experience in this area, the fish near the bottom forming dense aggregations such as illustrated were estimated to be generally dominated by Atlantic herring with a mean length of about $25 \mathrm{~cm}$ (Fig. 1) (Nero et al. 2004; Jech and Michaels 2006).

\section{Resonance modeling}

The acoustic data are further explored through modeling the resonance scattering (Fig. 5; Table 1). Two of the three sample windows are illustrated explicitly (Fig. 1, depths of 55 and $182 \mathrm{~m})$, and the third $(82 \mathrm{~m})$ is from one of the windows in aggregation E (Fig. 2). As described above, the scattering model is taken directly from Nero et al. (2004). Although there were two dominant spectral peaks described above for the data in the upper water column, to fit models to some of the data, and with the restriction of using length distributions from trawls without modification, up to three sets of resonances were required: the two sets of resonances (one set per spectral peak) that were described above, and one to describe the "shoulder" at $2 \mathrm{kHz}$ of the $1.5 \mathrm{kHz}$ peak (Figs. $1 d$ and $5 a$ ). Two sets of resonances were required in another selected sample in the upper water column (Fig. 5b), while only one set of resonances was required in the samples near the seafloor (Fig. 5c).

The length distributions used in the scattering modeling of the resonances from the data collected at nighttime in the upper water column are illustrated (Fig. 6). Here, herring 
Fig. 4. Length distributions of each species of fish from various combinations of trawl samples: $(a)$ all combined (17 trawls), $(b)$ night, upper water column (five trawls), and $(c)$ day, near bottom (six trawls). There are likely samples from the upper water column contaminating the bottom data, since the trawl was fixed open and passed through the upper water column to reach the deeper depth. Also, the larger red fish in (a) were caught near the seafloor during the night. Note that all vertical axes scales are different.
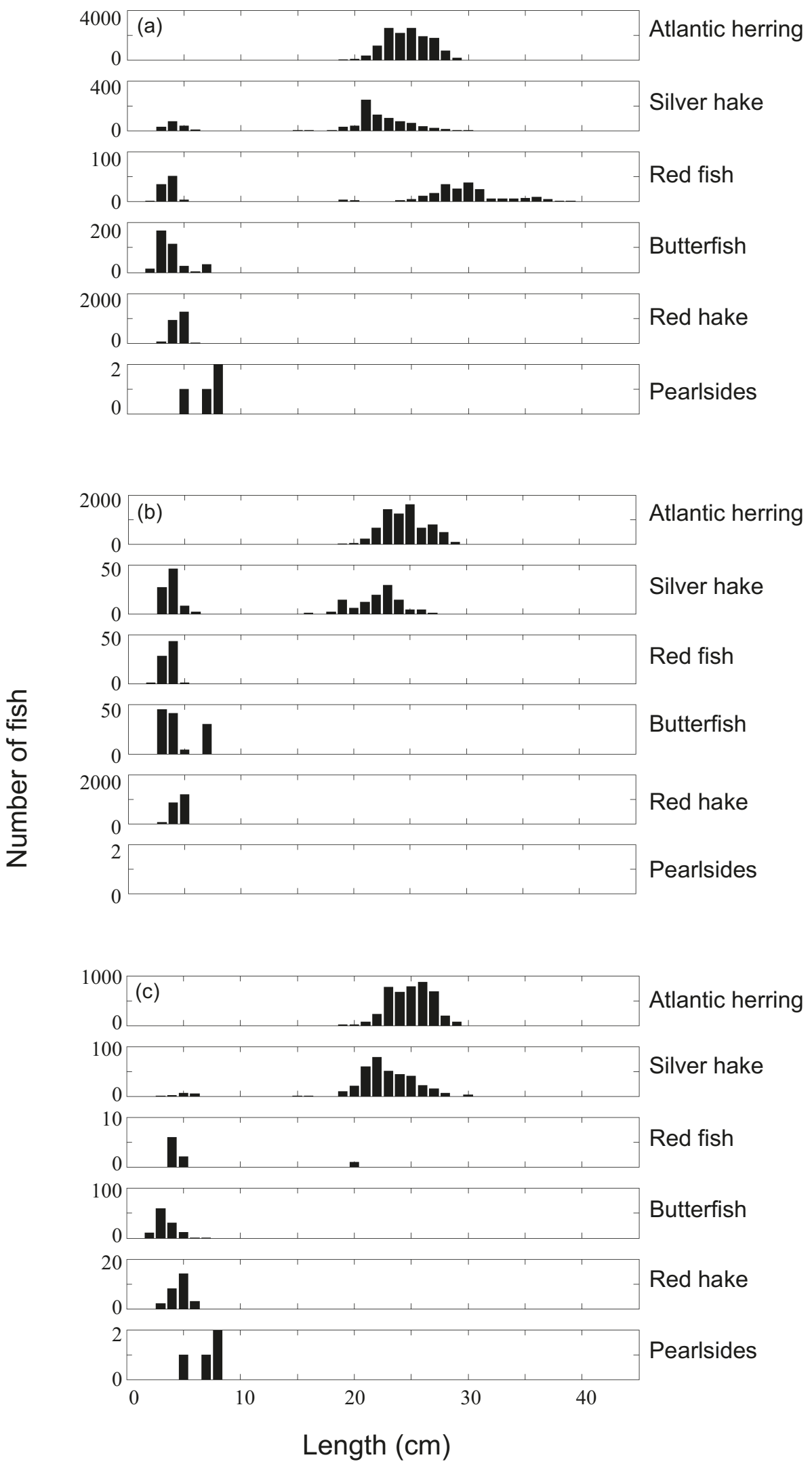
Fig. 5. Resonance modeling of broadband acoustic scattering data from sample windows at three different depths: (a) $55 \mathrm{~m}$ depth, aggregation J, night; (b) $82 \mathrm{~m}$ depth, aggregation E, night; (c) $182 \mathrm{~m}$ depth, aggregation RT4, day. Data from $(a)$ and $(b)$ were collected from the same night, but from different aggregations. The sample windows for $(a)$ and $(c)$ are illustrated in Fig. 1, while the sample window in $(b)$ is from Fig. 2. The herring resonance peak from each sample window is indicated by the arrows labeled " 1 ", " 2 ", and " 3 " in Fig. 3. Up to three sets of resonances are modeled. The scattering associated with each set of resonances is indicated by the thin broken lines. The composite scattering due to all sets of resonances is indicated by the thick solid line. Parameters of the modeling are given in Table 1 and in the text. The open circles in $(a)$ below $1.5 \mathrm{kHz}$ are drawn smaller to represent lower confidence in the measurements at the edge of the transducer spectral response.

and large silver hake are distinguished, but all small fish (including small silver hake) are combined. As discussed above, the length distributions used in the simulations are identical to the length distributions estimated from the trawls, with the exception of the need to use a finer resolution distribution for the small fish. In this latter case, the $1 \mathrm{~cm}$ size bins from the trawl were interpolated to $0.25 \mathrm{~cm}$ resolution, as shown in the figure. This adjustment was made to better match the relative resolution $(5 \%)$ of the larger fish. Also, the length distribution for large silver hake was only used for the modeling in the window from the depth of $55 \mathrm{~m}$. The length distribution used to model the daytime near-bottom data used herring data (from Fig. 4c) directly at the same $1 \mathrm{~cm}$ resolution.

For the purpose of illustration, the distribution of each of the three types or species of fish is normalized independently so that the area in each of the three histograms is unity (Fig. 6). The scattering predictions weight each simulated distribution by an inferred numerical density, $N$ (one per each of the three categories of fish), as illustrated (Table 1). Thus, when making reference to using the "same" size distribution, that means that they were the same on a normalized scale (that is, same shape), but the modeling involved uniformly scaling the distributions through use of the numerical density of fish.

\section{Discussion}

\section{Acoustical inference and issues}

The acoustic data, in combination with the trawl data, suggest one major size class of fish consistently near the seafloor and two consistently in the upper water column, where the spectral peak at the lower frequencies corresponds to larger fish and the spectral peak at the higher frequencies corresponds to smaller fish. Furthermore, for the reasons given below, there are most likely two types of fish contributing to the lower frequency peak in the upper water column - physostomous and physoclistous. This resonance information is used to infer variation of numerical density of the different size classes within the aggregations in the upper water column.

\section{Inference of sizes and types of fish}

In the upper water column, a correspondence between the two major peaks to the presumed Atlantic herring and small fish, as well as the shoulder of the herring resonance to the
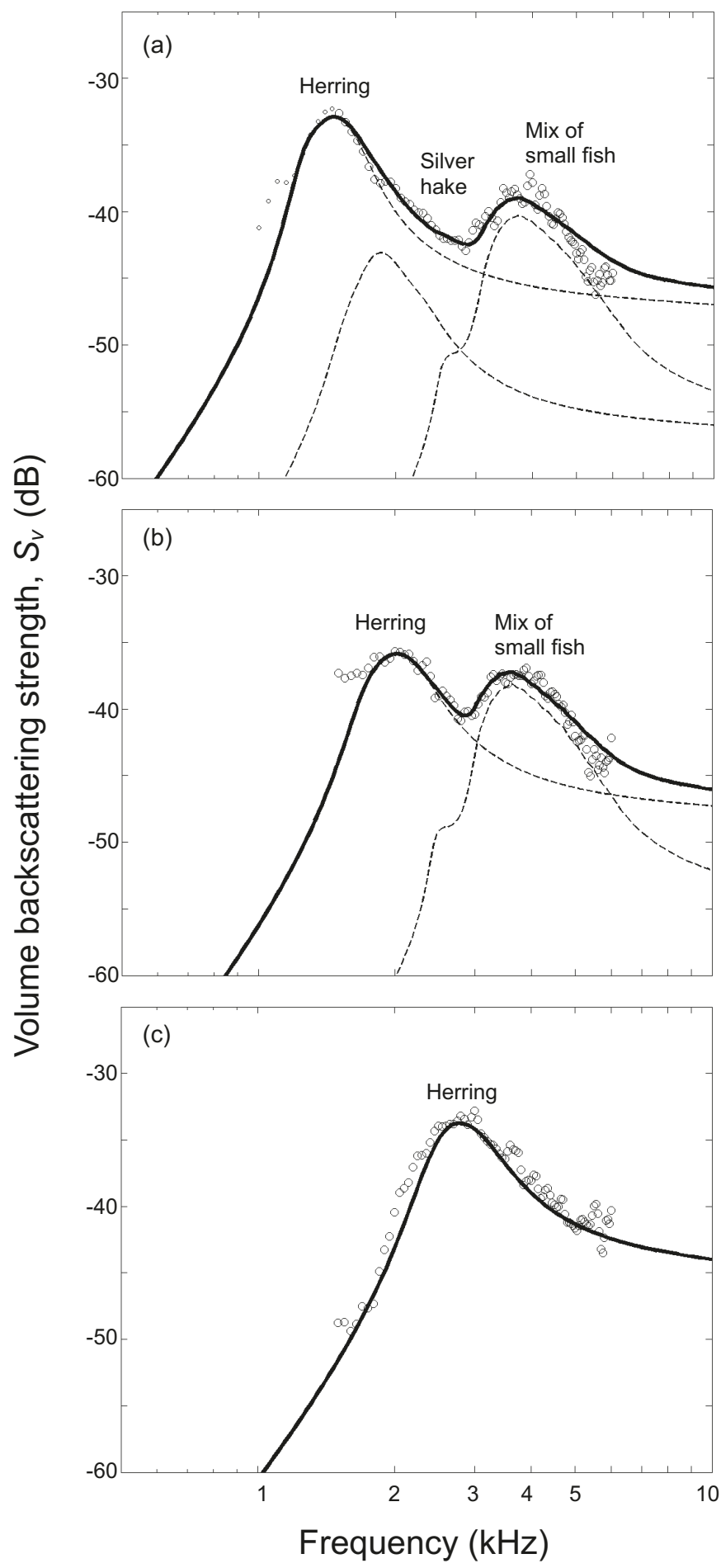

presence of silver hake, can be inferred from the resonance modeling. Some of this correspondence is consistent with the depth dependencies, or lack thereof, of the resonances. For example, the lower frequency peak at $2.0 \mathrm{kHz}$ and $82 \mathrm{~m}$ depth in aggregation $\mathrm{E}$ is shown to be part of a class of data following the $5 / 6$ power of depth, indicative of a physostome (herring). The lower frequency peak at $1.5 \mathrm{kHz}$ and $55 \mathrm{~m}$ depth in aggregation $\mathbf{J}$ occurs where there appears to be a mix of depth dependencies (whose analysis is complicated by the presence of the band edge). There are also data from near the seafloor that vary according to Boyle's law (aggre- 
Fig. 6. Length distributions of fish used in simulations corresponding to data collected at night in the upper water column. The data are based on trawl samples given in Fig. $4 b$. The herring and large silver hake distributions are taken directly, unaltered, from Fig. $4 b$. The distributions from all smaller fish (including small silver hake) from Fig. $4 b$ were combined into one group, "Mix of small fish". The resolution of the trawl samples is $1 \mathrm{~cm}$, although the simulations for the small fish required it to be interpolated to $0.25 \mathrm{~cm}$ as shown. The plots illustrate the length distributions used in the scattering modeling in Figs. $5 a$ and $5 b$, although while the large silver hake and herring are used along with the small fish in Fig. $5 a(55 \mathrm{~m})$, only the large herring (no large silver hake) along with the small fish are used in Fig. $5 b(82 \mathrm{~m})$. Each distribution is shown on a normalized scale (area in each distribution is unity).

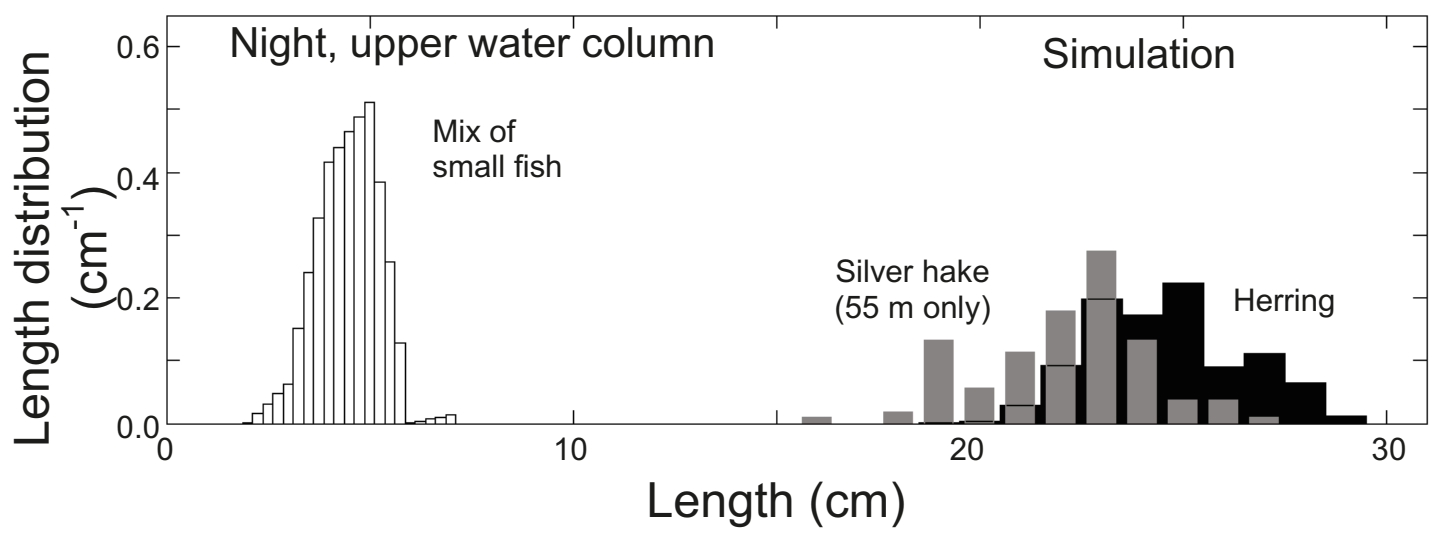

Table 1. Parameters of scattering models for each depth and category of fish.

\begin{tabular}{|c|c|c|c|c|c|c|}
\hline & \multicolumn{3}{|c|}{ Night $(55 \mathrm{~m})$} & \multicolumn{2}{|c|}{ Night $(82 \mathrm{~m})$} & \multirow{2}{*}{$\begin{array}{l}\text { Day }(182 \mathrm{~m} \\
\begin{array}{l}\text { Atlantic } \\
\text { herring }\end{array}\end{array}$} \\
\hline & $\begin{array}{l}\text { Atlantic } \\
\text { herring }\end{array}$ & $\begin{array}{l}\text { Silver } \\
\text { hake }\end{array}$ & $\begin{array}{l}\text { Small } \\
\text { mixed }\end{array}$ & $\begin{array}{l}\text { Atlantic } \\
\text { herring }\end{array}$ & $\begin{array}{l}\text { Small } \\
\text { mixed }\end{array}$ & \\
\hline $\bar{L}(\mathrm{~cm})$ & 24.6 & 22.1 & 4.5 & 24.6 & 4.5 & 25.0 \\
\hline$\sigma_{L}(\mathrm{~cm})$ & 1.9 & 2.0 & 0.76 & 1.9 & 0.76 & 1.8 \\
\hline$V_{\text {surf }}$ at $\bar{L}(\mathrm{cc})$ & 11 & 0.79 & 0.046 & 11 & 0.077 & 24 \\
\hline$V_{\text {depth }}$ at $\bar{L}$ (cc) & 1.7 & 0.79 & 0.046 & 1.2 & 0.077 & 1.3 \\
\hline$A$ & $2.3 \times 10^{-4}$ & $2.5 \times 10^{-5}$ & $3 \times 10^{-4}$ & $2.3 \times 10^{-4}$ & $5 \times 10^{-4}$ & $5 \times 10^{-4}$ \\
\hline$Q$ & 6.3 & 5.3 & 8.9 & 4.3 & 10 & 3.7 \\
\hline$\xi(\mathrm{Pa} \cdot \mathrm{s})$ & 30 & 30 & 5 & 50 & 5 & 80 \\
\hline$N\left(\mathrm{~m}^{-3}\right)$ & 0.4 & 0.075 & 0.6 & 0.45 & 0.6 & 0.85 \\
\hline
\end{tabular}

Note: Parameters are mean and standard deviation of fish length, $\bar{L}$ and $\sigma_{L}$, respectively; volumes of swimbladder (as estimated from modeling of the resonance) at the surface and depth of the sample window, $V_{\text {surf }}$ and $V_{\text {depth }}$, respectively, for the given mean fish length; the constant, $A$, in the swimbladder volume to fish length relationship, as determined empirically from the acoustic resonance data (i.e., from acoustically inferred volume of swimbladder); the quality factor, $Q$, of each resonance, as estimated for an individual fish; the viscosity parameter, $\xi$, of fish flesh; and the numerical density, $N$, of fish for each category, as inferred from the acoustic data. Also, the following parameters were fixed throughout the modeling: sound speed in water $c=1500 \mathrm{~m} \cdot \mathrm{s}^{-1}$; ratio of specific heats of air $\gamma=1.4$; and mass density of fish flesh $=$ $1050 \mathrm{~kg} \cdot \mathrm{m}^{-3}$ (Love 1978).

gation B), indicating that those fish are physostomes. Those data lie near the Boyle's law curve extrapolated from the upper water column (subset of data from aggregations D, E, J, K), suggesting that the fish from those two sets of data are the same size and species and that the fish is a physostome. The fact that the two curves with a 5/6 slope are offset from each other suggests that the physostomes are of slightly different sizes, as suggested by the differences in inferred $V_{\text {surf }}$ and differences in skew in size determined by the net sampling.

\section{Issues concerning depth dependence of resonances}

The independence (or weak dependence) upon depth of the fish in the upper water column producing resonance peaks at 1.5 and $3.7 \mathrm{kHz}$ is not consistent with an expected scattering response for either of the two types of swimbladders. For example, although the volume of the swimbladder of physoclists remains independent of depth (once adjusted to the depth), the resonance frequency still varies with depth according to a $1 / 2$ power. Another complicating factor in this interpretation is that physoclistous fish take time to adapt to a depth. In this latter case, the swimbladder may follow Boyle's law before it adjusts to the depth, temporarily resulting in a $5 / 6$ rather than $1 / 2$ power dependence upon depth (Sand and Hawkins 1973; Sundnes and Sand 1975; Løvik and Hovem 1979).

The above questions concerning the independence of depth of the resonance frequency remain unanswered in this current study, although it is important to note the connection between the spectral peak at the higher frequencies $(3.7 \mathrm{kHz} \pm$ $200 \mathrm{~Hz}$ ) in the upper water column and the presence of the $2-5 \mathrm{~cm}$ fish that are all physoclists. If the same mechanism that is apparently causing the $2-5 \mathrm{~cm}$ fish to have resonances that are independent of depth also applies to the $15-25 \mathrm{~cm}$ silver hake at those depths, then that would explain, at least in part, the independence of depth of the resonances near 
$1.5 \mathrm{kHz}$ (although note the qualification described above for resonances observed near the band edge of $1.5 \mathrm{kHz}$ ). This is not unreasonable to hypothesize, since there are also silver hake in the $2-5 \mathrm{~cm}$ size class. This fact, in combination with there being both silver hake and herring of similar size (15$30 \mathrm{~cm}$ range) in the upper water column, suggests that both physostomous and physoclistous fish in the upper water column are causing the same or similar resonance peak of $1.5 \mathrm{kHz}$.

\section{Comparisons of spectral peaks and swimbladder volumes with other studies}

Spectral peaks observed for near-bottom dwelling fish, presumed to be herring, were observed to be 2.5 and $3.7 \mathrm{kHz}$ at similar depths, location, and time of year in the studies of Nero et al. (2004) and Stanton et al. (2010), respectively. The peaks reported in this paper at $\sim 2.5-3.0 \mathrm{kHz}$ are more consistent with the data from Nero et al. (2004) than with those from Stanton et al. (2010). The 2.5-3.0 kHz peaks in this paper were observed during early daylight hours (first light to early morning), the $2.5 \mathrm{kHz}$ peaks in Nero et al. (2004) were observed during both day and night, while the $3.7 \mathrm{kHz}$ peaks in Stanton et al. (2010) were observed during the day. Although the towbody deployed in Stanton et al. (2010) was towed deep near the fish, in contrast to it being towed near the surface in this current study, the system was calibrated at the depth at which it was towed in each of the studies. Note also that there is the appearance of a small, higher frequency peak near $5 \mathrm{kHz}$ in the Nero et al. (2004) data, suggesting the presence of two size classes of fish in that study as well.

Since the observed spectral peaks at $182 \mathrm{~m}$ depth in this study are similar to the strong peaks observed in Nero et al. (2004) and the same scattering model was used, then the inferred volume of the swimbladder of the herring in this study is similar to that inferred by Nero et al. (2004) at that depth. However, the inferred volume of the herring at this and the other depths are higher than those predicted by the regression equation in Fässler et al. (2009). In that study, three-dimensional images of the swimbladder were formed in a laboratory using a magnetic resonance imaging system for a single dead herring (total length $=25.0 \mathrm{~cm}$ ) for pressures up to the equivalent of $60 \mathrm{~m}$ depth. Our inferred volumes at depths of 55 and $82 \mathrm{~m}$ were about $70 \%$ higher than those predicted by Fässler et al. (2009) at each of those depths. However, our inferred volume at $182 \mathrm{~m}$ was four times that predicted by Fässler et al. (2009). Given how little information is available on the volumes of swimbladders at these depths, this remains a research question.

\section{Inference of density variations of different size classes}

The above resonance and trawl information can be used to infer the variations of density of the different size classes of fish. For example, if the changes in volume backscattering strength of the higher resonance peaks in aggregations $\mathrm{E}$ and $\mathrm{J}$ were simply equated to changes in numerical density (that is, assuming that the backscattering strength varies as 10 times the logarithm of numerical density), then the observed decreases of 7 and $14 \mathrm{~dB}$ would correspond to decreases in numerical density by factors of 5 and 25 , respectively. However, the resonance scattering characteristics of fish with swimbladders may also vary with depth, which needs to be accounted for.

\section{Issues associated with inferring density}

At resonance, the backscattering cross-section is proportional to the product of the square of the equivalent spherical radius of the swimbladder and the square of the quality factor (Love 1978). The equivalent spherical radius of the swimbladder of the physostome decreases with depth according to Boyle's law. However, the radius of the swimbladder of the physoclist remains constant with depth. There is very little information regarding the depth dependencies of the quality factor of the different types of swimbladders, as reviewed in Diachok (2005). Data from shallow depths (fish at depths $<60 \mathrm{~m}$ ) show that the quality factor of some physostomes increases linearly with depth. That same linear relationship holds for one species of physoclists (cod; Løvik and Hovem 1979), while the quality factor is constant for another species of physoclist (coalfish; Diachok 2005), both for shallow depths. For deeper depths (>150-200 m), other scattering mechanisms dominate, and the quality factor for cod decreases with depth (Sand and Hawkins 1973). Once accounting for the various depth dependencies (shallow depths, such as in the upper water column in this study), the backscattering cross-section at resonance will vary according to the $4 / 3$ power of depth for the physostome and, for the physoclist will either be constant with depth for a constant quality factor or vary according to the square of depth for the variable quality factor.

These dependencies suggest that for a hypothetical case of a constant numerical density of physoclists, the volume backscattering coefficient (which is the linear form of the volume backscattering strength) should monotonically increase approximately with the square of depth at resonance (variable quality factor) or remain constant in the case of the quality factor being independent of depth. Likewise, the volume backscattering coefficient for a constant numerical density of physostomes should monotonically increase with depth according to the $4 / 3$ power of depth.

The observed trend of the scattering level of each resonance of each aggregation is either a very weak dependence upon depth or it contains a peak in the mid-depth portion, suggesting that the density varies with depth, perhaps differently for the large and small fish. With an assumption that the herring dominate the lower resonance and follow the above $4 / 3$ dependence upon depth, then these data suggest that the herring are concentrated more toward the upper portion of the aggregation, while the small fish are either concentrated more toward the upper portion or the middle portion of the aggregations, depending upon what depth dependency their quality factors follow. Furthermore, the smaller fish in aggregation $\mathrm{J}$ have a much stronger tendency toward being located at or above the middle of the aggregation than in aggregation $\mathrm{E}$. If the larger silver hake dominated the lower spectral peak, then they were more concentrated in the upper or middle portions of the aggregations. Regardless of which depth dependence the resonance frequency follows for each species, all resonances throughout each aggregation are strong, indicating the presence of all sizes of fish throughout each aggregation. 


\section{Quality of acoustic data}

Interpretation of the resonances is also subject to the quality of the acoustic data, which is not uniform across the frequency band, although generally the quality is very high. For example, the data were calibrated through averaging hundreds of pings from a precision-made standard target (sphere), resulting in an accuracy of the values of $S_{v}$ in the $1.5-6 \mathrm{kHz}$ range to be within $1 \mathrm{~dB}$. In addition, the SNR was 25$30 \mathrm{~dB}$ at the spectral peak associated with the herring and was at least $20 \mathrm{~dB}$ for all frequencies between the peak and the upper edge of the band at $6 \mathrm{kHz}$. The quality varied more at the lower band edge of $1.5 \mathrm{kHz}$. For example, at $55 \mathrm{~m}$ depth in aggregation $\mathrm{J}$, the (herring) peak occurred at the lower band edge with a SNR of $25 \mathrm{~dB}$ (Fig. 5a). However, while the SNR was also $25 \mathrm{~dB}$ at the lower band edge at $82 \mathrm{~m}$ depth in aggregation $\mathrm{E}$, it was only $3 \mathrm{~dB}$ at that edge at $182 \mathrm{~m}$ depth in aggregation RT4 (Figs. $5 b$ and $5 c$, respectively). Furthermore, for frequencies below $1.5 \mathrm{kHz}$, the slope of the spectral response of the system was relatively high and was a potential source of greater error in the calibration. Because of that high slope, the data were generally not shown, except for the case in Fig. $5 a$, where the SNR was $15 \mathrm{~dB}$ at $1.0 \mathrm{kHz}$ and the data were shown with small symbols, indicating uncertainty in the quality. In all three plots, the data were higher than the model predictions at the lowest frequency. The discrepancies in Figs. $5 a$ and $5 c$ can be explained, in part, by the data being in the high slope of the calibration curve (below band edge) or having poor SNR, respectively. The presence of larger fish not caught by the trawl, but causing the elevated levels at the lowest frequencies, cannot be ruled out.

\section{Acoustics-trawl comparison and associated errors}

Biological interpretation of the data was subject to the connections made between the acoustic and trawl data, as well as accuracy of model parameters. As discussed above, the resonance predictions were constrained with data from the combined trawl samples. While trawl samples were not identically colocated with the acoustic samples, the acoustic and net transects were all in the same $5 \mathrm{~km} \times 5 \mathrm{~km}$ area and were of comparable length, and the fish remained in this region throughout the study. Furthermore, had they been colocated, there would have remained errors associated with matching sample volumes of the trawl and the acoustic beam, as well as the size-dependent catch efficiency of the trawl. In addition, there was error due to the unknown relationship between the swimbladder volume and the fish length, and hence one relationship was used with an inferred coefficient. The coefficient sometimes needed to vary with depth.

\section{Other modeling approaches}

An alternative to the modeling approach used in this paper is to use the trawl samples as an initial condition and then modify the shapes of the modeled fish size distributions for the best fit between modeled spectral peaks and acoustic data. The result would be inferred size distributions of fish. In this case, there are far more model parameters (one per length bin in addition to the other scattering parameters), which allows for much more flexibility in fitting the resonance curves to the data. As attractive as this approach is, the current approach was chosen given the objective nature of using the trawl samples directly and the lack of knowledge of the key parameters of the models, such as acoustic damping factors of the swimbladder and swimbladder volume to fish size relationship. Another major issue involves the depth dependence of the resonance scattering properties, which depends not only on whether the fish is a physostome or physoclist, but also on its ability, and associated time, to adapt to changes in depth. In future studies, these various properties could be estimated independently rather than inferred from the acoustic data. In that case, and assuming an accurate scattering model, a broadband signal such as the one used in this study could be used to infer size distribution directly in a more general inversion of the data (Holliday 1977a, 1977b).

\section{Ecological inferences}

The broadband acoustic data revealed important behaviors of the fish. For example, the persistent occurrence of the mixed assembly of fish $<10 \mathrm{~cm}$ long in the upper water column suggests these species are coexisting for at least as long as the week-long study period. Hypotheses are that these fish are located in the upper water column to avoid predation, their food resources are abundant in this region, or both. The two species of larger fish present in the trawl samples were Atlantic herring and silver hake. During the study period, Atlantic herring were in the process of developing their gonads for spawning and hence were feeding very little to not at all (Collette and Klein-MacPhee 2002). However, after the herring have spawned and begin to feed, they can predate on small fish, such as small silver hake (J.M. Jech, Northeast Fisheries Science Center, unpublished data). The presence of the $>20 \mathrm{~cm}$ silver hake in the trawl hauls, as well as the inclusion of the "silver hake shoulder" in the acoustic modeling, suggest they are colocated with these smaller fish and presumably are predating on the smaller fish as well as zooplankton.

It is unknown whether these larger hake reside in the upper water column or migrate at night to feed. Their density was acoustically inferred to be $0.075 \mathrm{~m}^{-3}$ at one of the depths As adult silver hake typically reside near the bottom, those that move up in the water column must be enduring an expanded swimbladder if they are transient (similar to gadoids (e.g., Arnold and Greer Walker 1992) and coregonids (TeWinkel and Fleischer 1999)), or they have adapted to the shallower depth and are resident for some period of time. In either case, the energetic benefit to these hake (i.e., sufficient resources and reduced competition) should outweigh the costs of leaving the demersal zone. When or why these hake migrate up to this layer and what proportion of the local population utilizes this resource are unknown, but the presence of these fish suggests that this layer provides adequate resources for some individuals and the lower density suggests that this resource is not for the entire local population.

The presence of the elevated (left) shoulder at about $1.7 \mathrm{kHz}$ of the spectral peak within aggregation E may suggest the presence of larger predators at night. Tuna schools are regularly encountered during the NMFS herring survey, as noted by bird and marine mammal observers who routinely make visual observations during the NMFS survey. In addition, blue fish (Pomatomus saltatrix) are captured in mid-water trawls during the NMFS survey in this area, 
although none were captured during this study. The lack of these species in the trawl catches does not preclude their presence, but the spectral location of the shoulder suggests juveniles of these species may be predating in this layer.

It appears that while the upper water column is not a complete refuge from predation, it provides a suitable haven for juvenile or young-of-year pelagic and semidemersal species. In addition to potentially reducing predation risk, to coexist these smaller fish must be able to partition resources or the resources must not be limiting. Acadian redfish, silver hake, and red and white hake in this size range $(2-5 \mathrm{~cm})$ have similar diets and primarily feed on copepods, euphausiids, amphipod and decapod crustacea, mysids, and chaetognaths (Bowman 1981, 1984; Bowman et al. 1987). Butterfish also have a similar diet but can also feed heavily on ctenophores and salps (Oviatt and Kremer 1977), thus potentially reducing overlap with the other species. Pearlsides feed primarily on small zooplankton (Collette and Klein-MacPhee 2002) and, although are not thought to reside in the upper water column, could compete for resources when they are at shallow depths. Using the upper frequency bands of the broadband system, detection and quantification of zooplankton is possible (Stanton et al. 2010). These data could be used to estimate the prey resources, and a bioenergetics approach could be undertaken to investigate whether the available resources are limiting or sufficient and whether residence in this layer is a viable strategy for optimizing growth.

Finally, mixing or colocation of species within an aggregation such as in this study, as well as mixing in a layer or even in a school, is not uncommon. Observations of species mixing are prevalent in coral reef ecosystems (e.g., Ehrlich and Ehrlich 1973; Barlow 1974), and while less so for open-water environments, there are a number of examples of mixed aggregations in pelagic fish communities (see reviews in Shaw 1978; Pitcher 1986; Fréon and Misund 1999). Clupeid species can mix with Engraulids (Hobson 1963), Atlantic mackerel (Scomber scombrus) (Fréon and Misund 1999), sprat (Sprattus sprattus) (Rudstam et al. 1988), or other species (Parrish 1989). In most mixed aggregations there is a dominance of one species, and while the lesser-abundant individuals can benefit from joining a larger school (e.g., improved food detection; hydrodynamic advantages; reduced predation), if they are sufficiently different (visually or behaviorally) from the majority, they can be preferentially predated (Hobson 1963).

An alternative hypothesis to the "mixed species aggregation" is that the spectral peak between 3 and $4 \mathrm{kHz}$ in the shallow aggregations is due to Atlantic herring with very little gas in their swimbladder. For the $20-30 \mathrm{~cm}$ herring to have had a resonance frequency between 3 and $4 \mathrm{kHz}$ at the observed depths, the amount of gas in their swimbladder would need to be a very small fraction of normal volumes. The pre-spawning herring were in approximately the same developmental phase, the size distribution was unimodal, and the herring were not feeding; thus it seems unlikely that physiological state (e.g., fat content, stomach fullness, and gonad size) was responsible for two separate spectral peaks. Expelling gas has been observed in herring that are avoiding predators (Nøttestad 1998) or possibly communicating (Wilson et al. 2003). During this study period there were numerous predators of herring visually observed, so the occurrence of herring that may have expelled their gas is possible. The extent to which they expel gas is unknown, and it is not possible to confirm or refute the possibility that herring with nearly depleted swimbladders are present and are wholly or partly responsible for the higher spectral peak. If they were present, then it appears that they joined other herring with fuller swimbladders and did not immediately swim to the surface to re-inflate their swimbladder after expulsion.

The relative paucity of in situ observations of spatial mixing of species may be due to technological and environmental limitations, rather than an actual rarity of occurrence. Most observations of species spatially mixing are inferred from trawl or seine catches, but trawl catches are easily contaminated by organisms outside of the target area unless an opening-closing mechanism is employed in the cod end (e.g., Foote et al. 1996). Visual observations of schools can provide details of the spatial arrangement within schools such as species-segregated layers (Parrish 1989) or clusters (Hobson 1963), but these are extremely difficult to obtain owing to sampling volume limitations of optical technologies and avoidance by the fish, especially in pelagic realms. The broadband system finally provides an unobtrusive way (excluding potential ship-avoidance issues) to examine the internal fine-scale spatial structure of schools without behavior or size obscuring interpretation.

\section{Key accomplishments and remaining challenges}

A new broadband echosounder has been demonstrated to be a valuable tool in studying mixed assemblages of fish. The use of broadband acoustics represents a significant improvement over narrowband systems, which cannot (spectrally) discriminate between spatially unresolved fish of varying sizes within a given aggregation. Furthermore, this new system and associated new methods are a significant improvement over all previous types of broadband approaches where an aggregation cannot be studied quantitatively or at such high spatial resolution via pulse-compression processing, or both.

Through the use of the broadband sound and signal processing, two major size classes of fish with swimbladders were spectrally resolved and classified. Using broadband calibration, the relative strengths of the echoes from each size class were calculated, leading to inferences of the distribution of the different sizes of fish within an aggregation. The "shoulder" of one of the two major spectral peaks suggested the presence of a third set of resonances, which corresponded to the presence of fish with a slightly different size distribution within the major size class. Whether this was a different species of fish than that causing the major peak remains an open question.

This study shows the great potential this broadband approach has for studying fish ecology such as predator-prey interactions. For example, the scattering spectra revealed that a mix of small fish were colocated with their potential predator, silver hake, over the 1-week period of study in the upper water column. These results suggest that the upper water column was a suitable haven for the small fish despite the risks of predation.

In addition to discriminating size classes of fish, as demonstrated in this study, the long-range goal for broadband acoustics is to conduct a full inversion of the data in which the size distribution is inferred from a combination of trawl 
sampling and modeling of scattering. However, there are many challenges involving interpretation of the data that first need to be overcome in realizing that goal. For example, there are key parameters of fish anatomy and their acoustic scattering characteristics that need to be quantified for each species under investigation. These include (i) relationship between swimbladder volume and fish length, (ii) depth dependence of swimbladder volume, (iii) depth-change adaptation time of swimbladder volume, and (iv) acoustic damping factors of the swimbladder. Papers cited earlier in this article on these topics and for selected species illustrate the complexity of those parameters as well as the strong dependence upon species.

\section{Acknowledgements}

We are grateful to Orest Diachok of the Applied Physics Laboratory of the Johns Hopkins University, Laurel, Maryland, for his thoughtful suggestions in the early stages of this work; Brian Guest and Josh Eaton of the Woods Hole Oceanographic Institution (WHOI), Woods Hole, Massachusetts, for their assistance in preparation for and conducting the ocean experiment; and Shirley Barkley of WHOI for her assistance in preparing the manuscript. We also acknowledge the contributions of the captains and crews of the R/V Endeavor and FR/V Delaware II, as well as the reviewers of this paper for their thoughtful recommendations. This research was supported by the US Office of Naval Research (grant Nos. N00014-04-1-0440 and N00014-10-1-0127), NOAA - National Marine Fisheries Service; and the J. Seward Johnson Chair of the WHOI Academic Programs Office.

\section{References}

Arnold, G.P., and Greer Walker, M. 1992. Vertical movements of cod (Gadus morhua L.) in the open sea and the hydrostatic function of the swimbladder. ICES J. Mar. Sci. 49(3): 357-372. doi:10.1093/ icesjms/49.3.357.

Barlow, G.W. 1974. Extraspecific imposition of social grouping among surgeonfishes (Pisces: Acanthuridae). J. Zool. 174(3): 333340. doi:10.1111/j.1469-7998.1974.tb03161.x.

Batzler, W.E., and Pickwell, G.V. 1970. Resonant acoustic scattering from gas-bladder fishes. In Proceedings of an International Symposium on Biological Sound Scattering in the Ocean, Warrenton, Va., 31 March - 2 April 1970. Rep. 005. Edited by G.B. Farquhar. Maury Center for Ocean Science, Washington, D.C. pp. $168-179$.

Bowman, R.E. 1981. Food of 10 species of northwest Atlantic juvenile groundfish. Fish Bull. 79: 200-206.

Bowman, R.E. 1984. Food of silver hake, Merluccius bilinearis. Fish Bull. 82: 21-35.

Bowman, R.E., Azarovitz, T.R., Howard, E.S., and Hayden, B.P. 1987. Food and distribution of juveniles of seventeen northwest Atlantic fish species, 1973-1976. NOAA Techn. Memo. NMFS-F/ NEC-28.

Chapman, R.P., and Marshall, J.R. 1966. Reverberation from deep scattering layers in the western North Atlantic. J. Acoust. Soc. Am. 40(2): 405-411. doi:10.1121/1.1910087.

Chapman, R.P., Bluy, O.Z., Adlington, R.H., and Robison, A.E. 1974. Deep scattering layer spectra in the Atlantic and Pacific Oceans and adjacent seas. J. Acoust. Soc. Am. 56(6): 1722-1734. doi:10.1121/1.1903504.

Collette, B.B., and Klein-MacPhee, G. 2002. Bigelow and Schroeder's fishes of the Gulf of Maine. 3rd ed. Smithsonian Institution Press, Washington, D.C.
Diachok, O. 2002. Bioacoustic absorption spectroscopy: estimation of the biomass of fish with swimbladders. Bioacoustics, 12: 271274.

Diachok, O. 2005. Bioacoustic absorption spectroscopy: a new approach to monitoring the number and lengths of fish in the ocean. In Sounds in the sea: from ocean-acoustics to acoustical oceanography. Edited by H. Medwin. University Press, Cambridge, UK. pp. 398-410.

Diachok, O., Liorzou, B., and Scalabrin, C. 2001. Estimation of the number density of fish from resonance absorptivity and echo sounder data. ICES J. Mar. Sci. 58(1): 137-153. doi:10.1006/jmsc. 2000.0997.

Ehrlich, P., and Ehrlich, A. 1973. Coevolution: heterotypic schooling in Caribbean reef fishes. Am. Nat. 107(953): 157-160. doi:10. $1086 / 282823$.

Fässler, S.M.M., Fernandes, P.G., Semple, S.I.K., and Brierley, A.S. 2009. Depth-dependent swimbladder compression in herring Clupea harengus observed using magnetic resonance imaging. J. Fish Biol. 74(1): 296-303. doi:10.1111/j.1095-8649.2008.02130. x. PMID:20735542.

Feuillade, C., Nero, R.W., and Love, R.H. 1996. A low-frequency acoustic scattering model for small schools of fish. J. Acoust. Soc. Am. 99(1): 196-208. doi:10.1121/1.414503.

Foote, K.G., Ostrowski, M., Røttingen, I., Engås, A., Hansen, K.A., Hauge, K.H., Skeide, R., Slotte, A., and Torgersen, Ø. 1996. Acoustic abundance estimation of the stock of Norwegian spring spawning herring, winter 1995-1996. ICES C.M. 1996/H:33.

Fréon, P., and Misund, O.A. 1999. Dynamics of pelagic fish distribution and behaviour: effects on fisheries and stock assessment. Fishing News Books, Oxford, U.K.

Gauss, R.C., Fialkowski, J.M., Menis, J., Kunz, E.L., Stanton, T.K., Sellers, C.J., and Jech, J.M. 2009. Measurements and modeling of midfrequency clutter from fish aggregations over Georges Bank in the Gulf of Maine. J. Acoust. Soc. Am. 125: 2642.

Gorska, N., and Ona, E. 2003. Modeling the effect of swimbladder compression on the acoustic backscattering from herring at normal or near-normal dorsal incidences. ICES J. Mar. Sci. 60(6): 13811391. doi:10.1016/S1054-3139(03)00142-5.

Hahn, T.R. 2007. Low frequency sound scattering from spherical assemblages of bubbles using effective medium theory. J. Acoust. Soc. Am. 122(6): 3252-3267. doi:10.1121/1.2793610. PMID: 18247737.

Hall, M. 1981. Measurements of acoustic volume backscattering in the Indian and southern oceans. Aust. J. Mar. Freshwater Res. 32(6): 855-876. doi:10.1071/MF9810855.

Hobson, E.S. 1963. Selective feeding by the gafftopsail pompano, Trachinotus rhodopus (Gill), in mixed schools of herring and anchovies in the Gulf of California. Copeia, 1963(3): 595-596. doi:10.2307/1441506.

Hoffman, J.C., Bonzek, C.F., and Latour, R.J. 2009. Estimation of bottom trawl catch efficiency for two demersal fishes, the Atlantic croaker and white perch, in Chesapeake Bay. Mari. Coastal Fish. 1(1): 255-269. doi:10.1577/C08-048.1.

Holliday, D.V. 1972. Resonance structure in echoes from schooled pelagic fish. J. Acoust. Soc. Am. 51(4B): 1322-1332. doi:10. 1121/1.1912978.

Holliday, D.V. 1977a. Extracting bio-physical information from the acoustic signatures of marine organisms. In Oceanic sound scattering prediction. Edited by N.R. Andersen and B.J. Zahuranec. Plenum, New York. pp. 619-624.

Holliday, D.V. 1977b. The use of swimbladder resonance in the sizing of schooled pelagic fish. Rapp. P.-V. Reun.- Cons. Int. Explor. Mer, 170: 130-135.

Horne, J.K., and Jech, J.M. 1999. Multi-frequency estimates of fish 
abundance: constraints of rather high frequencies. ICES J. Mar. Sci. 56(2): 184-199. doi:10.1006/jmsc.1998.0432.

Jech, J.M., and Michaels, W.L. 2006. A multifrequency method to classify and evaluate fisheries acoustics data. Can. J. Fish. Aquat. Sci. 63(10): 2225-2235. doi:10.1139/f06-126.

Love, R.H. 1978. Resonant acoustic scattering by swimbladderbearing fish. J. Acoust. Soc. Am. 64(2): 571-580. doi:10.1121/1. 382009 .

Løvik, A., and Hovem, J.M. 1979. An experimental investigation of swimbladder resonance in fishes. J. Acoust. Soc. Am. 66(3): 850854. doi:10.1121/1.383238.

McCartney, B.S., and Stubbs, A.R. 1970. Measurements of the target strength of fish in dorsal aspect, including swimbladder resonance. In Proceedings of an International Symposium on Biological Sound Scattering in the Ocean, Warrenton, Va., 31 March - 2 April 1970. Rep. 005. Edited by G.B. Farquhar. Maury Center for Ocean Science, Washington, D.C. pp. 180-211.

Medwin, H., and Clay, C.S. 1998. Fundamentals of acoustic oceanography. Academic Press, Boston, Mass.

Nero, R.W., Thompson, C.H., and Jech, J.M. 2004. In situ acoustic estimates of the swimbladder volume of Atlantic herring (Clupea harengus). ICES J. Mar. Sci. 61(3): 323-337. doi:10.1016/j. icesjms.2003.09.006.

Nero, R.W., Feullade, C., Thompson, C.H., and Love, R.H. 2007. Near-resonance scattering from arrays of artificial fish swimbladders. J. Acoust. Soc. Am. 121(1): 132-143. doi:10.1121/1. 2382277. PMID:17297769.

Nøttestad, L. 1998. Extensive bubble release in Norwegian springspawning herring (Clupea harengus) during predator avoidance. ICES J. Mar. Sci. 55(6): 1133-1140. doi:10.1006/jmsc.1998.0416.

Oviatt, C.A., and Kremer, P.M. 1977. Predation on the ctenophore, Mnemiopsis leidyi, by butterfish, Peprilus triacanthus, in Narragansett Bay, Rhode Island. Chesap. Sci. 18(2): 236-240. doi:10. 2307/1350867.

Parrish, J.K. 1989. Layering with depth in a heterospecific fish aggregation. Environ. Biol. Fishes, 26(2): 79-85. doi:10.1007/ BF00001024.
Pitcher, T.J. (Editor). 1986. Functions of shoaling behaviour in teleosts. In The behaviour of teleost fishes. Johns Hopkins University Press, Baltimore, Md. pp. 363-440.

Rudstam, L.G., Lindem, T., and Hansson, S. 1988. Density and in situ target strength of herring and sprat: a comparison between two methods of analyzing single-beam sonar data. Fish. Res. 6(4): 305-315. doi:10.1016/0165-7836(88)90001-X.

Sand, O., and Hawkins, A.D. 1973. Acoustic properties of the cod swimbladder. J. Exp. Biol. 58: 797-820.

Shaw, E. 1978. Schooling fishes. Am. Sci. 66: 166-175.

Simmonds, J., and MacLennan, D. 2005. Fisheries acoustics: theory and practice. Blackwell Science Ltd., Oxford, UK.

Stanton, T.K., and Chu, D. 2008. Calibration of broadband active acoustic systems using a single standard spherical target. J. Acoust. Soc. Am. 124(1): 128-136. doi:10.1121/1.2917387. PMID:18646960.

Stanton, T.K., Chu, D., Jech, J.M., and Irish, J.D. 2010. New broadband methods for resonance classification and high-resolution imagery of fish with swimbladders using a modified commercial broadband echosounder. ICES J. Mar. Sci. 67(2): 365-378. doi:10.1093/icesjms/fsp262.

Sundnes, G., and Sand, O. 1975. Studies of a physostome swimbladder by resonance frequency analyses. J. Cons. Int. Explor. Mer, 36: 176-182.

TeWinkel, L.M., and Fleischer, G.W. 1999. Vertical migration and nighttime distribution of adult bloaters in Lake Michigan. Trans. Am. Fish. Soc. 128(3): 459-474. doi:10.1577/1548-8659(1999) $128<0459$ :VMANDO $>2.0 . \mathrm{CO} ; 2$.

Thompson, C.H., and Love, R.H. 1996. Determination of fish size distributions and areal densities using broadband low-frequency measurements. ICES J. Mar. Sci. 53(2): 197-201. doi:10.1006/ jmsc.1996.0022.

Wilson, B., Batty, R.S., and Dill, L.M. 2003. Pacific and Atlantic herring produce burst pulse sounds. Proc. R. Soc. Lond. B Biol. Sci. 271(Suppl. 3): S1-S3.

Ye, Z. 1997. Low-frequency acoustic scattering by gas-filled prolate spheroids in liquids. J. Acoust. Soc. Am. 101(4): 1945-1952. doi:10.1121/1.418225. 